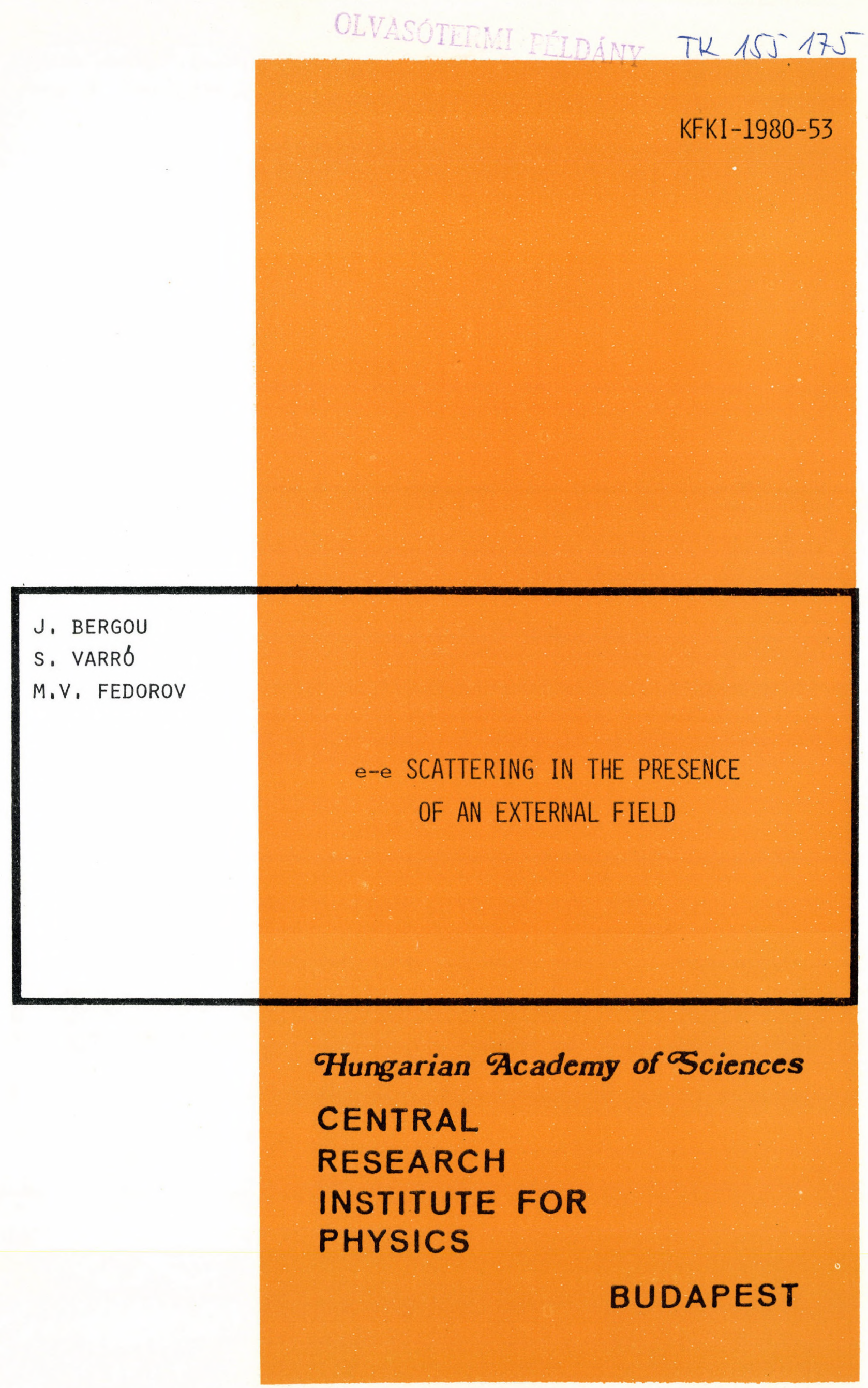




\title{
e-e SCATTERING IN THE' PRESENCE OF AN EXTERNAL FIELD
}

\author{
$\mathrm{J}$. Bergou and S. Varró
}

\begin{abstract}
Central Research Institute for Physics
H-1525 Budapest, P.O.B. 49, Hungary
\end{abstract}

and

\section{M.V. Fedorov}

P.N. Lebedev Physical Institute

of the Academy of Sciences of the USSR

Moscow, Leninsky prospect 53, USSR 


\section{ABSTRACT}

A nonrelativistic treatment is given of electron-electron scattering in the presence of a laser field. The field is accounted for by the external field approximation and is represented by a circularly polarized monochromatic plane-wave field. A simple analytic expression is derived for the transition amplitude which is shown to exhibit internal resonances as well as intensity dependent shifts. The former is the nonrelativistic limit of the resonant Mфller scattering predicted previously by Oleinik (1967a). The latter, however, appears in a higher order of $\mathrm{v} / \mathrm{c}$ and is consequently negligible for very slow electrons. The differential cross section of the scattering is also given where the effect of the spin and symmetry is taken into account explicitly. The width of resonances is introduced phenomenologically but its connection with previous methods is established. Consideration is also given to the experimental conditions under which the effects may become observable.

\section{АННОТАЦИЯ}

Излагается нерелятивистский метод описания электрон-электронного рассеяния в присутствии лазерного поля. Поле описывается в приближении внешнего поля и представляется циркулярно-поляризованным, монохроматическим, плосковолновым полем. Получено простое выражение для амплитуды перехода, которое показывает внутренние резонансы и сдвиги, зависящие от интенсивности. Резонансы представляют собой нерелятивистский предел резонансного меллеровского рассеяния, предсказанного Олейником. Однако сдвиги появляются только в более высоком порядке от $\mathrm{v} / \mathrm{c}$, и поэтому в случае медленных электронов ими можно пренебречь. Дифференциальное сечение рассеяния приведено к Форме, где влияние спина и симметрии явно имеется в виду. Ширина резонансов введена феноменологическим образом, но определяется ее связь с более точными методами. Обсуждаются экспериментальные условия, при которых эффекты станут наблюдаемыми.

\section{KIVONAT}

Megadjuk a lézertér jelenlétében végbemenô elektron-elektron szórás nemrelativisztikus leirását. A teret külsõtér-közelitésben tárgyaljuk és egy cirkulárisan polarizált monokromatikus sikhullámmal reprezentáljuk. Egyszerü analitikus kifejezést származtatunk az átmeneti amplitudóra, amelyrôl megmutatjuk, hogy számot ad a belsố rezonanciákról és az intenzitástól függõ eltolódásokról is. Az előbbi jelenség az oleinik (1967a) által elōrejelzett rezonáns Mфller szórásnál látottak nemrelativisztikus határesete, az utóbbi azonban csak v/c magasabb rendjeivel jelenik meg, következésképpen nagyon lassu elektronokra elhanyagolható. A szórás differenciális hatáskeresztmetszetét szintén megadjuk, amelyben a spint és a szimmetriát explicite figyelembe vesszük. A rezonanciák szélességét fenomenologikusan vezetjük be, de megmutatjuk a korábbi módszerekkel való kapcsolatát. Megvizsgáljuk azt is, hogy az effektusok milyen kisérleti feltételek mellett válnak észlelhetõvé. 


\section{INTRODUCTION}

In connection with the rapid development of high power lasers, in the last two decades considerable theoretical effort has been devoted to the description of fundamental EM processes in the presence of an intense field. of particular interest are the electromagnetic processes of free charged particles in such an environment. The theory developed so far (e.g. Mitter 1975 and Karapetyan and Fedorov 1978) predicts two different types of corrections whose physical origin is also entirely different. Namely, intensitydependent resonances and intensity-dependent shifts are the main phenomena occurring in external field problems. The occurrence of resonances is connected with induced processes at integer multiples of the frequency of the external field, whereas the occurrence of intensity dependent (energy and momentum) shifts is a classical effect connected with the average kinetic energy and momentum of a classical particle oscillating in an external field. Well known examples of these phenomena are the nonlinear bremsstrahlung (Bunkin and Fedorov, 1965) and nonlinear Compton scattering (Brown and Kibble 1964) in the presence of an intense external field. Especially interesting and much less commonly investigated are, in this context, the resonances and shifts predicted for M $\phi$ ller scattering. The problem was first investigated by Oleinik ( $1967 a$ and b). His results, however, were not given in a form suitable for direct comparison with experiments. Very recently, the problem was reinvestigated using a different calculational technique developed especially to treat intense field problems (Bös, Brock, Mitter and Schott, $1979 \mathrm{a}$ and b). The formalism was still rather complicated and allowed the calculations for nonrelativistic energies only. In view of this we think that the present status of the theory requires a consistent, nonrelativistic treatment of this problem.

The calculations are based on the formalism where the laser field is taken into account exactly and all the other interactions are treated by perturbation theory (Bergou, 1980). The laser field is represented as an external (classical) plane-wave field. In order to simplify the calculations we introduce a few assumptions which are essentially very similar to the assumptions of Bös et al. (1979a), namely: 
- the external field is circularly polarized

- consideration is given to nonrelativistic unpolarized electrons

- the e-e interaction takes place via the static Coulomb potential

- there is no transverse-photon exchange

- interaction with the spin-momentum is neglected.

The last four assumptions indicate that we use a consistent nonrelativistic description from the very beginning. As a result we obtain a simple analytical expression for the transition amplitude in Section 2. The kinematics of the process can easily be deduced from the delta-function parts of the transition amplitude. In Section 3 we transform the transition amplitude to a form where the internal resonances appear explicitly and we then derive the cross section of the scattering. We also discuss how the inclusion of the spin and symmetry modifies the preceding results. In the last part of the paper (Section 4) we briefly summarize the main results, give a physical interpretation to the internal resonances and discuss their connection with experimental possibilities of observation.

\section{THE TRANSITION AMPLITUDE}

In the following we shall investigate nonrelativistic electron-electron scattering in the presence of an external field. For an intense (laser) field the one-mode, external field approximation is reasonably good provided that the following two requirements are satisfied (Bergou and Varró, 1980b):

- the number of photons in the mode is large

- the change of the photon number (depletion) in a given process is much less than the initial number of photons. For a nonrelativistic approximation this change should actually be less than the ratio of electron rest energy to photon energy $\left(2 \mathrm{mc}^{2} / \hbar \omega\right)$ which, in the case of optical frequencies, is still a large number $\left(10^{5}-10^{6}\right)$.

We start from the Schrödinger equation of the problem:

$$
i \hbar \frac{\partial \psi}{\partial t}=H \psi
$$

where $\psi$ is the two-electron wavefunction and the Hamiltonian $\mathrm{H}$ can be written in the form

$$
\mathrm{H}=\mathrm{H}_{\mathrm{O}}+\mathrm{V}(\mathrm{r})
$$

where

$$
H_{0}=\frac{1}{2 m}\left(\hat{\underline{\hat{p}}}_{1}-\frac{\mathrm{e}}{\mathrm{c}} \underline{\mathrm{A}}\left(\nu_{1}\right)\right)^{2}+\frac{1}{2 m}\left(\underline{\hat{\underline{p}}}_{2}-\frac{\mathrm{e}}{\mathrm{c}} \underline{\mathrm{A}}\left(\nu_{2}\right)\right)^{2}
$$


and

$$
v(r)=e^{2} \frac{e^{-\alpha r}}{r}, \quad r=\left|\underline{x}_{1}-\underline{x}_{2}\right|
$$

$\mathrm{H}_{\mathrm{O}}$ corresponds to the free electrons interacting with the external field. The external field itself is represented by the $\underline{A}(\nu)$ vector potential

$$
A\left(v_{1,2}\right)=a\left(\underline{e}_{1} \cos v_{1,2}+\underline{e}_{2} \sin v_{1,2}\right), \quad v_{1,2}=\omega t-\underline{k x}_{1,2}
$$

which describes a circularly polarized plane wave. The electron-electron interaction is represented by the static Coulomb-potential (2.4). The shielding factor $\alpha$ is introduced here merely to simplify the following calculations. Its physical significance will be discussed in Section 4.

First, it should be noted that in dipole approximation ( $\underline{k}=0)$, the Schrödinger equation (2.1) can be decoupled in centre-of-mass and relative coordinates

$$
\psi\left(\underline{x}_{1}, \underline{x}_{2}, t\right)=\varphi_{1}(\underline{R}, t) \varphi_{2}(\underline{r}, t), \quad \underline{R}=\frac{1}{2}\left(\underline{x}_{1}+\underline{x}_{2}\right), \underline{r}=\underline{x}_{1}-\underline{x}_{2}
$$

to yield

$$
\operatorname{i\hbar } \frac{\partial \varphi_{1}}{\partial t}=\left[\frac{\hat{\underline{\mathrm{P}}}^{2}}{2 \mathrm{M}}-\frac{2 \mathrm{e}}{M \mathrm{C}} \underline{\mathrm{AP}}+\frac{4 \mathrm{e}^{2}}{2 M c^{2}} a^{2}\right] \varphi_{1}
$$

and

$$
\operatorname{ith} \frac{\partial \varphi_{2}}{\partial t}=\left[\frac{\hat{\mathrm{p}}^{2}}{2 \mathrm{~m}_{\mathrm{r}}}+\mathrm{V}(\mathrm{r})\right] \varphi_{2}
$$

Here $\hat{\hat{p}}$ and $\hat{p}$ are the respective operators of total and relative momenta, $M=2 \mathrm{~m}$ is the total mass, $m_{r}=m / 2$ is the reduced mass. We can easily recognize that Eq. (2.7) corresponds to the motion of a free particle (with total charge $2 \mathrm{e}$ and mass $2 \mathrm{~m}$ ) in an external field, whereas Eq. (2.8) is the Schrödinger equation of a particle moving in a background potential field $V(r)$. Since now the scattering problem is entirely separated from the external field problem, we immediately see that the external field affects the scattering only if we go beyond dipole approximation (Brehme 1971, Bergou 1976).

Let us now return to the full Hamiltonian (2.2) which is beyond dipole approximation. According to the spirit of intense field calculations we shall treat $V(r)$ as a perturbation and use the solution of the $H_{0}$ part as a basis set for perturbation theory. Since $\mathrm{H}_{\mathrm{O}}$ is the sum of two one-electron Hamiltonians, the unperturbed solution can be taken in the form of the product of two one-electron wavefunctions: 


$$
\psi^{(0)}\left(\underline{x}_{1}, \underline{x}_{2}, t\right)=\psi^{(0)}\left(\underline{x}_{1}, t\right) \psi^{(0)}\left(\underline{x}_{2}, t\right)
$$

The exact solution for $\psi^{(0)}(\underline{x}, t)$ - which is given in terms of Mathieu func-. tions and is therefore rather complicated - was found recently (Bergou and Varró, 1980a). However, for all practical purposes, the following approximative solution is satisfactory (ibid. and Ehlotzky, 1978):

$$
\psi^{(0)}=\psi_{\underline{p}}(\underline{x}, t)=(2 \pi \hbar)^{-3 / 2} e^{\frac{1}{\hbar}(\underline{p} \underline{x}-E t)} \exp \left[\underline{\frac{1}{h}} \int^{\nu}\left(\frac{e}{m c \omega}, \underline{A} \underline{p}-\frac{e^{2} a^{2}}{2 m c^{2} \omega^{\prime}}\right) d \nu^{\prime}\right]
$$

where $E=\frac{p^{2}}{2 m}$ and $\omega^{\prime}=\omega\left(1-\frac{k \underline{k}}{m \omega}\right)$ is the Doppler-shifted frequency.

The required validity condition of the above solution is the following. One may expand both (2.10) and the exact solution into Fourier series of $e^{1 n \nu}$. The coefficients of this Fourier series satisfy a complicated recurrence relation in the case of the exact solution which can be shown to reduce to the simpler recurrence relation for the coefficients of the Fourier series of $(2.10)$ if $\frac{n \hbar \omega}{2 m c^{2} f(a)}<<1$, where $f(a)=\left[\left(1-\frac{p}{m c}\right)^{2}-\left(\frac{e a}{m c^{2}}\right)^{2}\right]^{1 / 2}$ is a slowly varying function of amplitude a. For a large range of the a values $f(a) \sim 1$, and the validity condition is well fulfilled in optical interactions. Performing the integration in $(2.10)$ we obtain

$$
\dot{\psi}_{p}(\underline{x}, t)=(2 \pi \hbar)^{-3 / 2} e^{\frac{1}{h}(\tilde{p} \underline{x}-\tilde{E} t)} \exp \left[1 \frac{e a}{m c \hbar \omega^{\prime}}\left(\underline{e}_{1} \underline{p}^{\prime} \sin \nu-\underline{e}_{2} \underline{p}^{\prime} \cos \nu\right)\right]
$$

where

$$
-\tilde{\underline{p}}=\underline{p}+\frac{e^{2} a^{2}}{2 m c^{2} \omega^{\prime}} \underline{k}, \quad \tilde{E}=E+\frac{e^{2} a^{2}}{2 m c^{2} \omega^{\prime}} \omega, \quad \underline{p}^{\prime}=\frac{\underline{p}}{1-\frac{\underline{k} \underline{p}}{m \omega}}
$$

We see that $\tilde{p}$ and $\tilde{E}$ depend nonlinearly on the original momentum $\underline{p}$ and contain an intensity dependent shift. $\mathrm{Q}^{\prime}$ reduces to $\mathrm{Q}$ in the case of very slow electrons.

With the help of first order perturbation theory we obtain for the transition amplitude due to $V(r)$ the expression

$$
T_{f 1}=-\frac{1}{\hbar} \int_{-\infty}^{\infty} d t \int d^{3} x_{1} d^{3} x_{2} \psi_{f}^{(0) *}\left(\underline{x}_{1}, \underline{x}_{2}, t\right) v(r) \psi_{i}^{(0)}\left(\underline{x}_{1}, \underline{x}_{2}, t\right)
$$


where

$$
\psi_{1}^{(0)}=\psi_{\underline{p}_{11}}\left(x_{1}, t\right) \psi_{\underline{p}_{21}}\left(\underline{x}_{2}, t\right), \quad \psi_{f}^{(0)}=\psi_{\underline{p}_{1 f}}\left(\underline{x}_{1}, t\right) \psi_{\underline{p}_{2 f}}\left(\underline{x}_{2}, t\right)
$$

are initial and final wavefunctions, respectively. Using expression (2.11) for $\psi_{\underline{Q}}(\underline{x}, t)$ in (2.12) we have the following explicit form of $\mathrm{T}_{\mathrm{f} 1}$ '

$$
\begin{aligned}
& T_{f 1}=-\frac{1}{\hbar} \frac{1}{(2 \pi \hbar)^{6}} \int_{-\infty}^{\infty} d t \int d^{3} x_{1} d^{3} x_{2} v(r) e^{\frac{1}{\hbar}\left[\Delta \tilde{p}_{1} \underline{x}_{1}+\Delta \tilde{p}_{2} \underline{x}_{2}-\left(\Delta \tilde{E}_{1}+\Delta \tilde{E}_{2}\right) t\right]} \\
& \cdot \exp \left[i z\left(\underline{e}_{1} \Delta \underline{p}_{1}^{\prime} \sin \nu_{1}-\underline{e}_{2} \Delta \underline{p}_{2}^{\prime} \cos \nu_{1}+\underline{e}_{1} \Delta \underline{p}_{2}^{\prime} \sin \nu_{2}-\underline{e}_{2} \Delta \underline{p}_{2}^{\prime} \cos \nu_{2}\right)\right]
\end{aligned}
$$

where

$$
z=\frac{e a}{m c \hbar \omega}, \quad \Delta \tilde{\underline{z}}=\tilde{p}_{1}-\tilde{p}_{f}, \quad \Delta \underline{p}^{\prime}=p_{1}^{\prime}-\underline{p}_{f}^{\prime}, \Delta \tilde{E}=\tilde{E}_{i}-\tilde{E}_{f}(2.13 a)
$$

If we now introduce centre-of-mass and relative coordinates:

$$
\underline{\mathrm{R}}=\frac{1}{2}\left(\underline{\mathrm{x}}_{1}+\underline{\mathrm{x}}_{2}\right), \quad \underline{\mathrm{r}}=\underline{\mathrm{x}}_{1}-\underline{\mathrm{x}}_{2}
$$

and centre-of-mass and relative momenta:

$$
\underline{p}=p_{1}+\underline{p}_{2}, \quad \underline{p}=\frac{1}{2}\left(p_{1}-p_{2}\right)
$$

then $T_{f 1}$ takes the form

$$
\begin{aligned}
& T_{f 1}=-\frac{1}{\hbar} \frac{1}{(2 \pi n)^{6}} \int_{-\infty}^{\infty} d t \int d^{3} R d^{3} r v(r) e^{\frac{1}{\hbar}\left[\Delta \underline{\underline{R}} \underline{R}+\Delta \tilde{\underline{p}} \underline{r}-\left(\Delta \tilde{E}_{1}+\Delta \tilde{E}_{2}\right) t\right]} . \\
& \cdot \exp \left\{1\left[-z_{1} \sin \frac{1}{2} \underline{k r} \cos (\omega t-\underline{k} \underline{R}+\varphi)+z_{2} \cos -\frac{1}{2} \underline{k} \underline{r} \sin (\omega t-\underline{k} \underline{R}+\Phi)\right]\right\}
\end{aligned}
$$

where

$$
\begin{array}{ll}
\underline{e}_{1} \Delta \underline{\mathrm{P}}^{\prime}=\Delta \mathrm{P}_{\perp}^{\prime} \cos \Phi, & \underline{\mathrm{e}}_{2} \Delta \underline{\mathrm{P}}^{\prime}=\Delta \mathrm{P}_{\perp}^{\prime} \sin \Phi \\
\underline{\mathrm{e}}_{2} \Delta \underline{\underline{p}}^{\prime}=\Delta \mathrm{p}_{\perp}^{\prime} \cos \varphi, & \underline{\mathrm{e}}_{2} \Delta \underline{\underline{p}}^{\prime}=\Delta \mathrm{p}_{\perp} \sin \varphi \\
z \Delta \mathrm{p}_{\perp}^{\prime}=\mathrm{z}_{1} & \mathrm{z} \Delta \mathrm{P}_{\perp}^{\prime}=\mathrm{z}_{2}
\end{array}
$$

after having made use of the trigonometric relations 


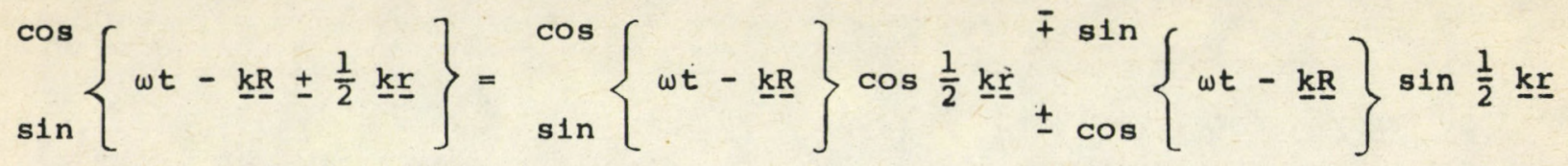

Using the expansions

$$
e^{1 z \sin \theta}=\sum_{\ell}^{J_{\ell}(z) e^{1 \ell \theta}} \text { and } e^{i z \cos \theta}=\sum_{m} 1^{m^{m}} J_{m}(z) e^{1 m \theta}
$$

In (2.14) the time and $\underline{R}$ integration can easily be carried out yielding

$$
\begin{aligned}
& T_{f 1}=-2 \pi 1 \sum_{\ell, n} \delta\left(\underline{\tilde{P}}_{\dot{f}}-\underline{\tilde{p}}_{1}+n \hbar \underline{k}\right) \delta\left(\tilde{E}_{f}-\tilde{E}_{1}+n \hbar \omega\right) . \\
& \frac{1}{(2 \pi \hbar)^{3}}(-1)^{\ell} \int d^{3} r V(r) J_{\ell}\left(z_{1} \sin \frac{1}{2} \underline{k r}\right) J_{n-\ell}\left(z_{2} \cos \frac{1}{2} \underline{k r}\right) e^{1(\ell \varphi+m \Phi)}
\end{aligned}
$$

where $\mathrm{n}=\ell+m$.

In the extreme nonrelativistic case (scattering of very slow electrons) $v / c<1$ and $\underline{\tilde{p}}=\underline{\mathrm{P}}^{\prime}=\underline{\mathrm{P}}$. Since $z_{2}$ is proportional with the transverse component of $\Delta \underline{P}^{\prime}=\underline{P}_{1}^{\prime}-\underline{P}_{f}^{\prime}$ according tQ the conservation of the transverse components of the centre-of-mass momentum expressed by the delta function, we have $z_{2}=0$ and $J_{n-\ell}(0)=\delta_{n, l}$. Consequently, in this case $T_{f i}$ can be represented as a single sum over $\mathrm{n}$-photon emitted and absorbed parts

$$
T_{f i}=\sum_{n} T_{f 1}^{(n)}
$$

where

$$
T_{f i}^{(n)}=-2 \pi i \delta\left(\tilde{E}_{f}-\tilde{E}_{i}+n \hbar \omega\right) \delta\left(\underline{P}_{f}-\underline{P}_{i}+n \hbar \underline{k}\right) t_{f i}^{(n)}
$$

and

$$
t_{f 1}^{(n)}=\frac{1}{(2 \pi \hbar)^{3}} e^{i\left(\varphi-n \frac{\pi}{2}\right)} \int d^{3} r v(r) J_{n}\left(z_{1} \sin \frac{1}{2} \underline{k r}\right) e^{\frac{i}{\hbar} \Delta \underline{\underline{h}} \underline{r}}
$$

From here we can deduce the following conservation laws:

- transverse components of $\underline{P}$ are conserved

- the longitudinal component of $\underline{p}$ is shifted by an amount which depends on the momentum itself and is proportional to the light intensitiy. Furthermore, in the process of scattering it may acquire an integer number of the photon momentum $\hbar \underline{k}$

- the energy is also shifted by an amount depending on the momentum and being proportional to the light intensity. Furthermore, during scattering it may change by an integer munber of the photon energy $n \omega$. 
The momentum shift $\delta \underline{P}$ is connected with the energy shift $\delta \mathrm{E}$ by the relation $|\delta P|=\frac{1}{C}|\delta E|$ and is therefore small even at high intensities. This justifies our process of neglecting the difference between $\underline{\tilde{P}}$ and $\underline{p}$ but keeping $\tilde{E}$ when we made the transition from $(2.15)$ to $(2.17)-(2.18)$.

The energy conservation law can be brought to a somewhat different form where the kinematics of the process is more apparent. The initial and final energies can be expressed with the help of the centre-of-mass and relative momenta as follows (to first order in $\mathrm{v} / \mathrm{c}$ ):

$$
E_{i, f}=E_{1 i, f}+E_{2 i, f}=\frac{\underline{p}_{i, f}^{2}}{4 m}+\frac{\mathrm{p}_{i, f}^{2}}{m}+2 \frac{e^{2} a^{2}}{2 m c^{2}}+\frac{e^{2} a^{2}}{2 m c^{2}} \frac{\underline{k} \underline{\underline{P}}}{m \omega}
$$

Conservation of energy requires now

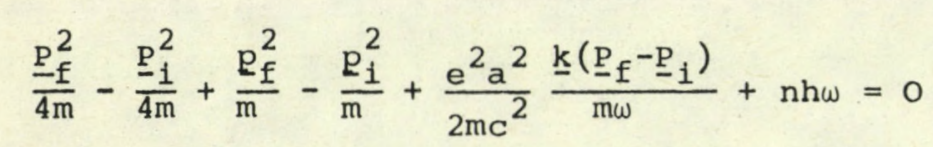

The uniform shift $\frac{\mathrm{e}^{2} \mathrm{a}^{2}}{2 \mathrm{mc}^{2}}$ cancels from the difference, only the nonuniform part of the shift $\frac{e^{2} a^{2}}{2 m c^{2}} \cdot \frac{\frac{k P}{i, f}}{m \omega}$ gives a nonvanishing contribution. We can now make use of the conservation law of the centre-of-mass momentum $\underline{\mathrm{P}}_{\mathrm{f}}=\underline{\mathrm{P}}_{\mathrm{i}}-\mathrm{nhk}$ in (2.19) yielding

$$
\frac{\underline{p}_{f}^{2}}{m}-\frac{p_{i}^{2}}{m}+n \hbar \omega\left(1-\frac{e^{2} a^{2}}{2\left(m c^{2}\right)^{2}}-\frac{v_{i}^{\prime \prime}}{c}\right)+n^{2} \frac{\hbar^{2} \omega^{2}}{4 m c^{2}}=0
$$

where $V_{i} "=c \frac{\frac{k P}{i}}{m \omega}$ is the longitudinal (parallel to $\underline{k}$ ) component of the initial centre-off-mass velocity.

In other words, the system takes on momentum as a whole (momentum change appears in the centre-of-mass motion). The corresponding Doppler shift and recoil together with an additonal intensity dependent energy shift appear in the relative motion. Equation (2.17) indicates that absorption and emission of real photons are also connected with the relative motion (for the process under consideration this means the internal degrees of freedom). To close this section, let us mention that in dipole approximation $\underline{k} \underline{r}=0, J_{n}(0)=\delta_{n, 0}$ and Eq. (2.18) gives the usual fieldless scattering amplitude as expected from Eqs. $(2.7)$ and $(2.8)$. 


\section{SCATTERING CROSS SECTION}

\subsection{INCLUSION OF SPIN AND SYMMETRY}

Since the electrons are fermions, the two-electron wavefunction must be antisymmetric under the exchange of the two particles. Accordingly, we have to modify the theory developed in the preceding section in order to include this symmetry property in the treatment. First, we note that the Hamiltonian (2.2) does not affect the spin variables hence the total wavefunction is a product of the spin-dependent and the coordinate-dependent terms. The wavefunction describing the spin state of the two particles may be elther symmetric (triplet state) or antisymmetric (singlet state) on the exchange of the particles. The corresponding orbital part is either antisymmetric (triplet state) or symetric (singlet state). The orbital part of the transition amplitude $\mathrm{T}_{f i}$ will then be either antisymetric $\left(\mathrm{T}_{f i, a}\right)$ or symmetric $\left(\mathrm{T}_{f i, \mathrm{~s}}\right)$. Since the effect of the exchange of the particles is equivalent to changing the sign of the relative momentum in the final state and therefore does not affect the centre-of-mass part of the transition amplitude, we have for the symmetric case

$$
T_{f i, s}=-2 \pi i \sum_{n} \delta\left(\tilde{E}_{f}-\tilde{E}_{1}+n \hbar \omega\right) \delta\left(\underline{P}_{f}-\underline{P}_{1}+n \hbar \underline{k}\right) t_{f 1, s}^{(n)}
$$

where

$$
\begin{aligned}
& t_{f i, s}^{(n)}=\frac{1}{(2 \pi h)^{3}} \int d^{3} r v(r)\left[e^{\frac{1}{\hbar} p^{(-)} \underline{r}} J_{n}\left(z^{(-)} \sin \frac{1}{2} \underline{k} \underline{r}\right) e^{i\left(n \varphi(-)-n\left(\frac{\pi}{2}\right)\right.}+\right. \\
& \left.+e^{i \underline{p}^{(+)} \underline{r}} J_{n}\left(z^{(+)} \sin \frac{1}{2} \underline{k} \underline{r}\right) e^{i\left(n \varphi^{(+)}-n \frac{\pi}{2}\right)}\right]
\end{aligned}
$$

and

$$
\begin{aligned}
& \mathrm{p}^{( \pm)}=\mathrm{p}_{1} \pm \mathrm{p}_{f^{\prime}} \quad \mathrm{z}^{( \pm)}=\frac{\mathrm{ea}}{\operatorname{mc\hbar } \omega}\left|\mathrm{p}_{1 \perp} \pm \mathrm{p}_{\mathrm{f}_{\perp}}\right| \\
& \varphi^{( \pm)}=\arctan \frac{\mathrm{e}_{2} \mathrm{p}^{(+)}}{\underline{\mathrm{e}}_{1} \mathrm{p}^{(+)}}
\end{aligned}
$$

Equation (3.2) can be written in the form

$$
t_{f 1, s}^{(n)}=t_{f 1}^{(n)}(\theta)+t_{f i}^{(n)}(\pi-\theta)
$$

where $t_{f i}^{(n)}(\theta)$ is the amplitude of transiton due to the $v(r) J_{n}\left(z_{1} \sin \frac{1}{2} \underline{k r}\right) e^{i \varphi}$ effective potential as given by Eq. (2.18) and $\theta$ is the scattering angle (the angle between $\mathrm{p}_{\mathrm{f}}$ and $\mathrm{p}_{\mathrm{i}}$ ).

Similarly, for the antisymmetric case we have 


$$
T_{f i, a}=-2 \Pi 1 \sum_{n} \delta\left(\tilde{E}_{f}-\tilde{E}_{1}+n \hbar \omega\right) \delta\left(\underline{P}_{f}-\underline{P}_{1}+n \hbar \underline{k}\right) t_{f 1, a}^{(n)}
$$

where now

$$
t_{f i, a}^{(n)}=t_{f i}^{(n)}(\theta)-t_{f i}^{(n)}(\pi-\theta)
$$

Quite generally, there are three symmetric and one antisymmetric spin states for the two-electron system. For unpolarized electrons each state is equally probable. Therefore, in the cross section the weight of the antisymmetric combination (3.6) is three times larger than the weight of the symmetric combination (3.2), that is,

$$
\frac{d \sigma^{(n)}}{d \Omega}=\frac{1}{4} \frac{d \sigma_{s}^{(n)}}{d \Omega}+\frac{3}{4} \frac{d \sigma_{a}^{(n)}}{d \Omega}
$$

The cross section $\frac{d \sigma}{d \Omega}$ is a sum of incoherent $n$-th order cross sections and (3.7) holds for each of them separately. In the following we shall confine ourselves to the study of the (unsymmetrized) $t_{f i}^{(n)}(\theta)$ scattering amplitude (2.18) since symmetrization is essentially equivalent with the inclusion of $t_{f i}^{(n)}(\pi-\theta)$ in the treatment and therefore effects connected with symmetry can be obtained by changing $\theta$ to $\pi-\theta$.

\subsection{INTERNAL RESONANCES}

To perform a numerical calculation for direct comparison with experiments we can most conveniently use Eq. (2.18). In order to get a better insight into the dynamics of the physical processes involved and to get a qualitative understanding of them, we transform the transition amplitude to a form where the internal resonances are manifest. We start from Eq. (2.18). Let us first introduce the Fourier representation of $v(r)$ as

$$
v(r)=\int v(q) e^{-i q \underline{r}} d^{3} q, \quad v(q)=\frac{4 \pi e^{2}}{q^{2}+\alpha^{2}}
$$

Then we use the integral representation for the Bessel function $J_{n}(x)$ (Abramowitz and Stegun, 1964):

$$
J_{n}(x)=\frac{1}{2 \pi} \int_{-\pi}^{\pi} e^{-i n \theta+i x \sin \theta} d \theta
$$

In our case $\mathrm{z} \sin \frac{1}{2} \underline{k} \underline{\underline{r}}=\mathrm{x}$. Inserting this expression for $\mathrm{x}$ in the exponential and expanding $e^{i z \sin \theta \sin } \frac{1}{2} \underline{k} \underline{r}$ in Fourier series of $e^{i \frac{m}{2} \underline{k} \underline{r}}$ we obtain for $t_{f i}^{(n)}$ from $(2.18)$ : 


$$
t_{f 1}^{(n)}=\frac{e^{1\left(n \varphi-n \frac{\pi}{2}\right)}}{(2 \pi \hbar)^{3}} \sum_{m} \int_{-\pi}^{\pi} d \theta e^{1 n \theta} J_{m}(z \sin \theta) \int d^{3} r d^{3} q e^{\frac{1}{n}\left(\Delta p+\frac{m}{2} h \underline{k}-n g\right) \underline{r}}
$$

Integration over $\underline{\mathrm{r}}$ yields the Dirac delta function $\delta\left(\Delta \underline{\mathrm{p}}-\mathrm{hg}+\frac{1}{2} \mathrm{~m} \hbar \underline{k}\right)$ and the integration over $\mathrm{q}$ ylelds then $\mathrm{v}\left(\underline{\mathrm{q}}=\frac{1}{2} \mathrm{mk}+\Delta \underline{p} / \mathrm{h}\right)$. The only remaining integral (integration over $\theta$ ) yields (Gradshtein and Ryzhik, 1971)

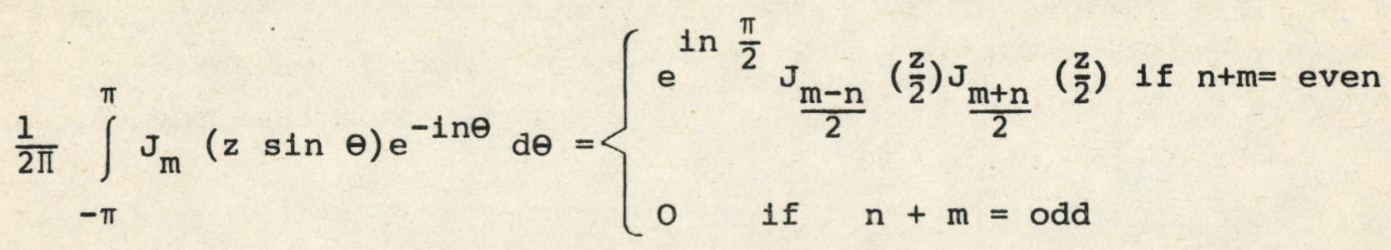

We can summarize the results as follows. The transition amplitude $\mathrm{T}_{\mathrm{fi}}$ can be represented by a sum of $n$-photon emitted $(n>0)$ and absorbed $(n<0)$ parts $T_{f i}^{(n)}$

$$
T_{f 1}=\sum_{n} T_{f 1}^{(n)}
$$

where

$$
T_{f 1}=-2 \pi 1 \delta\left(\underline{P}_{f}-\underline{P}_{1}+n \hbar \underline{k}\right) \delta\left(\tilde{E}_{f}-\tilde{E}_{i}+n \hbar \omega\right) t_{f i}^{(n)}
$$

Here $t_{f i}^{(n)}$ is given either by Eq. (2.18) - which is more convenient for practical numerical calculations - or by

$$
t_{f 1}^{(n)}=e_{\substack{m \varphi \\(m+n=\text { even })}}^{i n \frac{2 e^{2} \hbar^{2}}{\pi^{2}}} \cdot \frac{\frac{J_{m-n}}{2}\left(\frac{z}{2}\right) J_{\frac{m+n}{2}}\left(\frac{z}{2}\right)}{(2 \Delta \underline{p}+m \hbar k)^{2}+(2 \hbar \alpha)^{2}}
$$

The scattering amplitude given in this form explicitly exhibits a resonance structure. Apart from the Coulomb resonance $(\Delta \mathrm{p}=0)$ we have additional new resonances whenever $2 \Delta \mathrm{p}+\mathrm{m} \hbar \underline{k}=0$. Introducing a new summation index $\frac{m-n}{2}=r$ in (3.10) we obtain an equivalent but simpler form for $t_{f i}^{(n)}$ (we avoid the use of ostensibly fractional indices)

$$
t_{f 1}^{(n)}=e^{\ln \varphi} \sum_{r} \frac{e^{2} 2 \hbar^{2}}{\pi^{2}} \frac{J_{r}\left(\frac{z}{2}\right) J_{r+n}\left(\frac{z}{2}\right)}{[p+(2 r+n) \hbar k]^{2}+(2 \hbar \alpha)^{2}}
$$




\subsection{CROSS SECTION}

The cross section can be calculated in the usual manner from the square of the scattering amplitude $t_{f i}$. For unpolarized electrons we average over initial and sum over final spin states. Since the Hamiltonian (2.2) does not affect the spin state, this procedure actually leads to the weighted sum of symmetric and antisymmetric cross sections. Furthermore, similar to other processes in the presence of an external field, the differential cross section do is a sum of incoherent contributions d ${ }^{(n)}$ corresponding to $n$-photon absorption $(n<0)$ and emission $(n>0)$.

$$
d \sigma=\sum_{n} d \sigma^{(n)}
$$

where, according to Eq. (3.7),

$$
d \sigma^{(n)}=\frac{1}{4} d \sigma_{s}^{(n)}+\frac{3}{4} d \sigma_{a}^{(n)}
$$

In our system of normalization and with the help of Eqs. (3.4) and (3.6)

$$
d \sigma_{s}^{(n)}=\frac{p_{f}}{p_{i}}\left|\frac{2 m}{\hbar^{2}} t_{f i, s}^{(n)}\right|^{2} d \Omega
$$

and

$$
d \sigma_{a}^{(n)}=\frac{p_{f}}{p_{i}}\left|\frac{2 m}{\hbar^{2}} t_{f i, s}^{(n)}\right|^{2} d \Omega
$$

Using the explicit expressions (3.4) and (3.6) we obtain finally

$$
\frac{d \sigma^{(n)}}{d \Omega}=\frac{p_{f}}{p_{i}}\left(\frac{2 m}{\hbar^{2}}\right)^{2}\left\{\left|t_{f i}^{(n)}(\theta)\right|^{2}-\operatorname{Re}\left[t_{f i}^{(n)}(\theta) t_{f i}^{(n) *}(\pi-\theta)\right]+\left|t_{f i}^{(n)}(\Pi-\theta)\right|^{2}\right\}
$$

This expression clearly has the advantage over the ones given by Bös et al. (1979a) and Oleinik (1967a) that the average over polarization is explicitly carried out and the problem is reduced to its essence, i.e. to the manifestation of the internal resonances. In addition, $t_{f i}^{(n)}$ is given by two different but equivalent expressions, Eqs. (2.18) and (3.10). The first one is more convenient for performing numerical analysis, while the second one explicitly exhibits a resonance structure. Far from resonances the dependence of the denominator on the summation index can be neglected and the summation can be carried out to yield a closed form expression for the nonresonant scattering cross section. 


\section{DISCUSSION AND SUMMARY}

In the previous sections we have derived explicit expressions for the transition amplitude and scattering cross section of the nonrelativistic electron-electron scattering in the presence of an external electromagnetic field (laser). This scattering is the nonrelativistic limit of the Moller scattering in an external field (Oleinik 1967a and b, Bös et al. 1979a and b). We have found the previously predicted intensity-dependent shifts and resonances to persist in the nonrelativistic case as well. However, shifts appear in higher order in $\mathrm{v} / \mathrm{c}$ than resonances. In lowest order in $\mathrm{v} / \mathrm{c}$ there is still an intensity dependent shift of the kinetic energy and momentum of the free electron but it is uniform (i.e. independent of the state of the electron, which is characterized by $E$ and $p$ ). This uniform shift therefore cancels out in the transition amplitude which depends on differences of energy and momentum. Only the next order term (which is nonuniform, $1 . e$. p dependent) gives a nonvanishing contribution to the shift. But since the momentum shift $\delta P$ is related to the energy shift $\delta E$ via the relation $|\delta \mathrm{P}|=\frac{1}{\mathrm{C}}|\delta \mathrm{E}|$, the nonvanishing contribution to the momentum shift is in fact already second order in $1 / \mathrm{c}$ and in nonrelativistic approximation it can safely be neglected. Thus only the energy shift leads to observable consequences.

The advantage of the consistent nonrelativistic treatment is the possibility of carrying out explicitly the averageing over spin-polarization. We have obtained two different forms for the transition amplitude, viz. Eqs. (2.18) and (3.10). Equation (3.10) more explicitly shows the resonant structure and its connection with previous calculations is straightforward. On the other hand, Eq. (2.18) has a few advantages. First, it is more suitable for performing numerical calculations. Second, it allows an intersting interpretation for the occurrence of resonances. Apart from a phase factor, in first Born approximation the scattering can be interpreted as being caused by an effective potential $V_{\text {eff }}(\underline{r})=V(\underline{r}) J_{n}\left(z \sin \frac{1}{2} \underline{k} \underline{r}\right)$. It is clear at first sight that all effects of the external field result from the non-dipole character of the effective potential, since in the $\underline{k}=0$ case the scattering reduces to the coulomb scattering. For certain electron separation $\underline{r}$ this effective potential may become attractive $\left(J_{n}<0\right.$ ) which tends to cause the electrons to form pairs. It is known that to a bound state there corresponds a resonance in the scattering amplitude. Therefore the resonances in the scattering cross section might be regarded as the manifestation of the attractive effective potential between electrons in the presence of an external field. From (3.10) it is clear that in the case of a resonance the absorption and emission of virtual photons might be regarded as real processes (energy-momentum conservation is satisfied). The effect bears some analogy with the formation of electron pairs in superconductors through the electron-phonon interaction. However, for a resonance one must simultaneously satisfy conservation of energy-momentum in the virtual photon 
exchange (labelled by $\mathrm{m}$ in (3.10)) and conservation of the total energy-momentum (as described by the argument of the delta functions in (2.17)). At this point it should be mentioned that in our treatment we introduced phenomenologically a damping factor in the coulomb potential. Far from resonances the damping can be neglected and we are left with the usual Coulomb potential for the electron-electron interaction. In the vicinity of resonances the role of the radiative corrections becomes significant. As was discussed by Bös et al. (1979a and b), two types of radiative corrections have to be taken into account: vacuum polarization for the photon and self-energy correction for the electron. For slow electrons and optical photons the second of these is dominant. From their discussion it also follows that the distances between resonances are much larger than their width given by the radiative corrections. In beam experiments two other types of corrections have also to be taken into account. First, the finite width of the laser line; second, the finite width of the momentum distribution of the incoming electrons leads to further broadening effects. It seems to be hard to overcome this latter difficulty in the case of nonrelativistic electrons. Nevertheless, one can assume an ideal experimental situation and neglect the broadening due to these effects. In this case the resonant scattering occurs at very small scattering angles (near the coulomb resonance) and one needs high angular resolution but the effect is in principle observable.

We finally note that in homogeneous but time varying fields $(\underline{k}=0)$ the effect disappears and the external field has no influence at all on the scattering. This is not the case, however in the scattering of oppositely charged particles (e.g. bremsstrahlung). In that case the particles oscillate with opposite phases and this oscillatory motion enters the relative part of the equation of motion. One then obtains in the $\underline{k}=0$ limit a nonvanishing contribution which is the leading term and $\underline{k} \neq 0$ gives only small corrections. Thus the main effect of the external field is to distinguish between the relative signs of the scattered particles.

\section{REFERENCES}

Abramowitz M and Stegun I A 1964 Handbook of Mathematical Functions (Dover, London)

Bergou J 1976 Acta Phys. Hung. $40 \quad 55$

Bergou J $1980 \mathrm{~J}$. Phys. A (to appear in the August issue)

Bergou J and Varró S 1980 a J. Phys. A (to appear in the October issue) $1980 b$ submitted for publ. to J. Phys. A (Preprint KFKI 1980-14)

Bös J Brock W Mitter $\mathrm{H}$ and Schott Th 1979a J. Phys. A12 715 1979 b J. Phys. A 12573

Brehme H 1971 Phys. Rev'C $3 \quad 837$ 
Brown L S and Kibble T W B 1964 Phys. Rev 133 A705

Bunkin F V and Fedorov M V 1965 ZhETF 49

Ehlotzky F 1978 Opt. Comm. $27 \quad 65$

Gradshtein I S and Ryzhik J S 1971 Tables of integrals, sums, and series (Nauka, Moscow)

Karapetyan R V and Fedorov M V 1978 ZhETF $\underline{75} 816$

Mitter H 1975 Acta Phys. Austr. Suppl. 14397

Oleinik V P 1967a ZhETF 521049

$1967 \mathrm{~b}$ ZhETF $\underline{53} 1997$ 



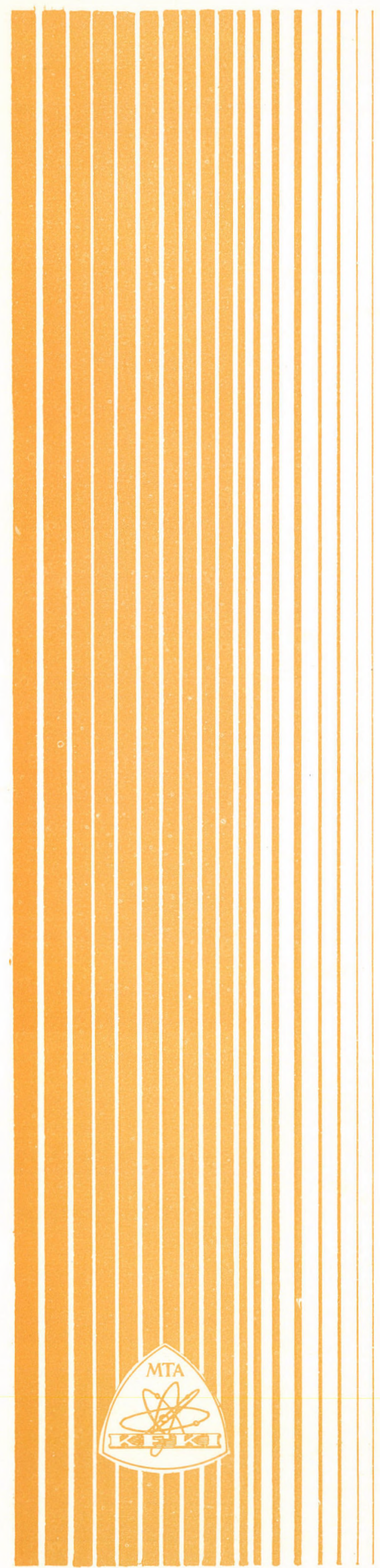

Kiadja a Központi Fizikai Kutató Intézet Felelõs kiadó: Krén Emil

Szakmai lektor: Fazekas Patrik Nyelvi lektor: Harvey Shenker

Példányszám: 465 Törzsszám: 80-509 Készült a KFKI sokszorositó üzemében Budapest, 1980. augusztus hó 